Journal of Engineering and Applied Sciences 14 (14): 4761-4766, 2019

ISSN: 1816-949X

(C) Medwell Journals, 2019

\title{
Packer Classification for Well Completion Design
}

\author{
${ }^{1,2}$ Claudia Marcela Hernandez, ${ }^{3}$ Robinson Perez and ${ }^{1}$ Cristian Rincon-Guio \\ ${ }^{1}$ Department of Research, Fundacion Universitaria Navarra (UNINAVARRA), Neiva, Colombia \\ ${ }^{2}$ Universidad Surcolombiana, Neiva, Colombia \\ ${ }^{3}$ Completion Services, Bogota, Colombia
}

\begin{abstract}
The packers are tools created to isolate and control fluids in the well and these become one of the most critical equipment to develop an adequate completion design, either for lower or upper completion. In the literature and in the different companies that provide these packers, they present different classifications which help in an initial approximation, to determine which packer should be selected, according to the function to be performed in the well. These classifications are not found in a clear way and neither a characterization that helps to make an appropriate selection of the equipment. In addition to the above, currently new technologies have been implemented for types of packers, operational applications and design that have not yet been categorized. According to the above, a detailed analysis was carried out, identifying the different classifications and categories that the packers may have as well as their description, characterization and relationship among them in order to achieve the adequate selection of this equipment for an optimal completion design.
\end{abstract}

Key words: Packer, seal bore, anchor, retrieve, seating, equipment

\section{INTRODUCTION}

Wells can be producers or injectors. Completions can produce oil, gas and water. Completions can inject hydrocarbon gases, water, steam and waste products such as carbon dioxide, Sulphur, hydrogen sulphide, etc. For more than one propose can be combined either simultaneously (e.g., produce the tubing and inject down annulus) or sequentially (produce hydrocarbons and then convert to water injection duty) (Bellarby, 2009). Due to the above, not all wells should be considered producers because they perform various services.

Well completion is defined as all works, configurations, equipment or necessary designs, from the conditioning of reservoir interest area to placing the well in service (injection or production).

Completion are often divided into the reservoir or lower completion (the connection between the reservoir and the well) and the upper completion (conduit from reservoir completion to surface facilities) (Bellarby, 2009).

According to Bellarby (2009), the lower completion method is divided into 5: barefoot, pre-drilled or slotted liner, cement and perforated liner or casing, open hole sand control screens/gravel pack and cased hole gravel pack or frac-pack and the upper completion methods can be divided in 4: tubing less completion, tubing completion without packer, tubing completion with annulus packer and dual tubing completion with packers in addition in the recent years a new type of completion has been implemented to improve the performance of the secondary and tertiary recoveries, this is the selective strings which are an extension of the third type of completion tubing with packer, that to develop its selectivity, this must use more than 2 packers and up to 18 have been installed.

Completion packers are one of the most important equipment for the completion can fulfill its function. There are many types and categories of Completion packers which directly impact in completion design for upper or lower completions and which must be selected in a rigorous manner, therefore, we will make a description about the completion packers and their different classifications, some of them very recognized but others not due to new packers in the market or its application in tubing stress analysis technique.

\section{PACKERS CLASSIFICATION}

Completion packers: According to Patton (1987) "The packer isolates and aids in the control of production fluids and pressures to protect the casing and other formations above or below the producing zone. All packers will attain one or more of the following objectives when they are functioning properly:

Corresponding Author: Cristian Rincon-Guio, Department of Research, Fundacion Universitaria Navarra (UNINAVARRA), St 10 \# 6-41, Neiva, Colombia 
- Isolate well fluids and pressures

- Keep gas mixed with liquids by using gas energy for natural flow

- Separate producing zones, preventing fluid and pressure contamination

- Aid in forming the annular volume (Casing/Tubing/packer) required for gas lift or subsurface hydraulic pumping systems

- Limit well control to the tubing at the surface for safety purposes

- Hold well servicing fluids (Kill fluids, packer's fluids) in casing annulus"

In addition to the above, the packers must satisfy two purpose, one is structural (anchor tubing to casing) and the second is sealing (Bellarby, 2009).

There are currently a wide variety of packers in the market for a variety of conditions and configurations possibly needed. Each packer design helps for a specific application and those packers are classified to help people to select and achieve an optimal completion design. Below we will detail these different classifications.

Completion packer classification: In the literature, there are described different classifications of packers such as: Guo et al. (2017) who describes a classification between conventional and swellable packers. Patton, cited by Guo et al. (2017) mentions that conventional packers are mechanically or hydraulically seating. Patton (1987) mentions the classification according to whether they are permanent or retrievable. Bellarby (2009) mentions the packer classification according to the hydraulic, hydrostatic or mechanical seating installation system and also mentions the classification retrievable or permanent. In addition, companies such as Schlumberger in their catalogs classify them in a general way as conventional packers and packers for other extreme services such as Dual, HPHT (High Pressure and High Temperature), intelligent, swellable among others (Anonymous, 2017a, b). Hughes (2017) classifies them in his catalog as permanent or retrievable and Anonymous (2017a, b) on their page classifies them as sealbore packer, single string packer and hydrostatic packer.

As described above, there are many ways to classify packers but, so far, it has not been clearly described each of them and the importance of these on the well completion design. Following, we list each one:

- Packer to casing anchor

- Tubing to packer connection

- $\quad$ String number

- Tube movement
- Seating system

- With o without retrievable system

- Retrievable system

- Completion type

Next, each of these classifications will be described detailed Fig. 1. This classification relates whether or not the packer is anchored to casing. One of the characteristics of this one is the capacity to remain anchored casing through the slips but there are some packers that do not have this system and only have rubbers to generate the seal, these are called "without anchoring". These packers may be applicable for lower and upper completion in the first is to generate annular seal between the casing and open hole, for this inflatable or sellable packers are used which will be described later. The packers called tandem are hydraulic released by tension or rotation forces which do not have slips and are used as intermediate packers in selective strings in order to generate lower costs. Because the lack of slips of these packers are sold cheaper than the packers with slips in addition, they are used as intermediate between packers with slips in order to anchor for tandem and prevent the completion stress movement of the packer and losing the seal.

The way to evaluate the efforts on the packages with wedges is by means of the operative envelope of the same while non-anchored packers (without slips) do not have an envelope and must be evaluated in a way special to determine where they can be installed or not Fig. 2 .

Tubing to packer connection classification is according to whether the pipe is integral or not to the packing, the subdivisions of this category are detailed below.

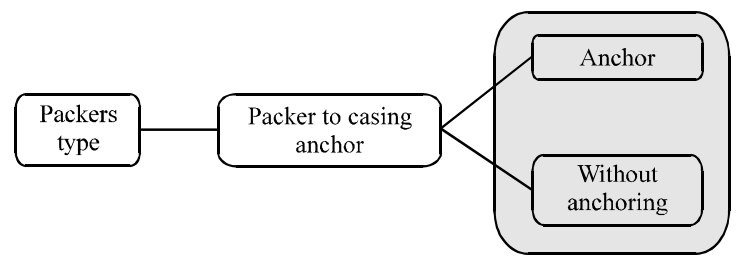

Fig. 1: Packer to casing anchor categories

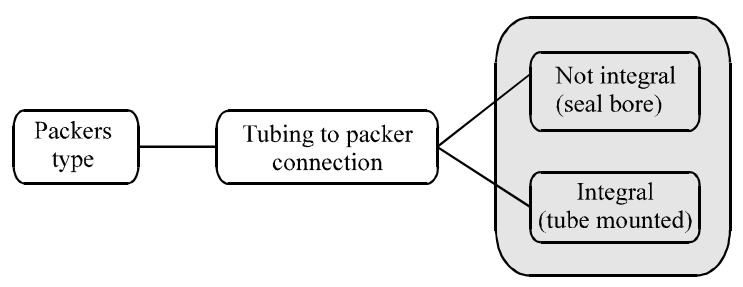

Fig. 2: Tubing to packer connection categories 
Integral packer: Are tubing connection by above and below of packer, this condition means that the movement generated by the tubing due to large changes in temperature and pressure cannot be generated due to connection to packer and these movements become in loads on the packers which can cause operational problems in the tubing and equipment of string such as damaging the rubber or generating tubing deformation (Calderon, 2017). These packers can be hydraulic, hydrostatic and mechanical seating, also Tandem packer mentioned above is included in this category.

Non-integral packer: In conditions where length changes of tubing completion become a problem, non-integral or seal bore types packers are used, packers of this type is not integral part of tubing and allows it to move freely through the seals unit, thanks to these seals the hydraulic isolation is ensured and no greater loads are generated on the tubing nor on the casing caused by the packer load (Calderon, 2017). These packers allow three types of tube movement which will be described in a later category Fig. 3.

Number of strings classification is made according to the number of tubing connected to the packer which can be of one or two strings. The most used packer connection is to a single tubing but two strings is hydraulic seating and tension retrieving and is normally, used to fulfill the function of a dual completion which is necessary for to perform functions in the two strings simultaneously. In addition, this packer is used in combination with electro submersible pumps allowing the bottom cable be connected to the motor passes through the secondary string Fig. 4. Tube movement classification is made according weather packers connection are integral and non-integral.

Integral packer: These packers for having the tubing to packer connection are considered anchored to it and due to this condition, all the stresses generated in the tubing during a service are transmitted to the packer.

Non-integral packer: These packers are also called seal bore packers, these packers are created to allow the tube movements and prevent the stress generated in tubing are transmitted to the packer for which three types of movements were created and can be generated according to the connection between the locator of the seals unit with the packer, these are: Anchored, restricted (No Go) and free, the first does not allow the tube movement and the tension and compression axial force generated are

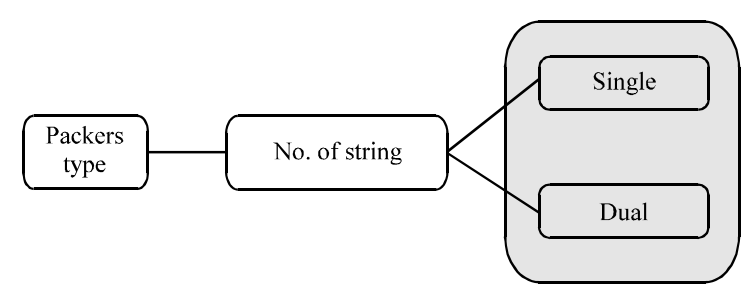

Fig. 3: Number of strings categories

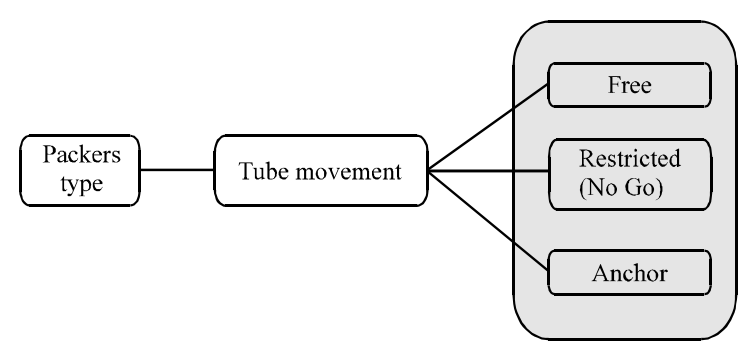

Fig. 4: Tube movement categories

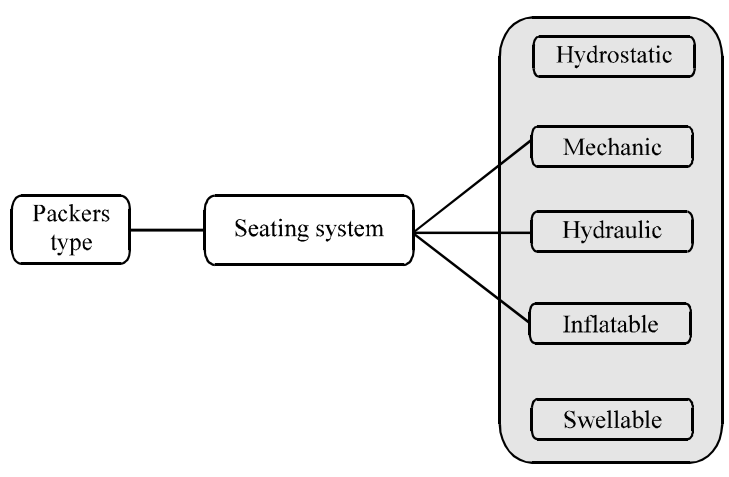

Fig. 5: Seating system categories

transmitted to the packer in the second, it allows movement only in an upward direction which does not allow tension forces to be transmitted to the packer but if it restricts the downward movement, for which the packer is affected by compression forces and finally, the third type is free movement in the two directions where the packer is not affected by any force.

This classification is very important because takes into account one of the most critical conditions to perform the completion design and tubing stress analysis technique Fig. 5. This classification mentions the different seating systems presented by the packers which are detailed in Fig. 5.

Hydrostatic seating: This packer only needs hydrostatic pressure for its seating and the differential pressure does not affect its functioning, therefor is not necessary to add plugs or isolation systems between the internal and 
annular pressure. This type of seating is characteristic of Integral packers and is used generally in deep or deviated wells where it is not possible to perform the run or installation of plugs to achieve a pressure differential.

\section{MECHANICAL SEATING}

This mechanical seating system uses a combination of actions between tension, compression and rotation that are generated from the surface in order to generate the seating. Integral packers usually useonly a single packerthat can be run for completion, since, it does not allow the torque transmission or movement to a second packer, so, they could not be applied for selective string completions. Although, there is a deviation of this type of packers which are not mentioned here, these service packers can be run jointly or in tandem with two of them, Recoverable Plug (RBP) and mechanical service packer, since, the two have different movements and can be generated by setting them up. These mechanical integral packers present restriction in deviated wells or with high DLS (Dog Leg Severity) due to the fact that the necessary torque for the seating cannot be transmitted.

On the other hand, there is a type of non-integral packer (Seal bore) that are also called mechanical seating, since, they need a seating tool either hydraulic or wireline (explosives), to generate the internal movement of the packer and thus, achieve its seating.

Hydraulic seating: Unlike, hydrostatic seating packer, these need a differential pressure between annular and tubing to seat the packer. To achieve this differential, it is necessary to place a plug at the bottom of the well below the packer. These packers like the hydrostatic are very used for the case of selective string completion, deviated or horizontal wells and in medium depths where this supports the stresses generated on the tubing.

Inflatable seating: This type of packer does not have slips and act by applying pressure and keeping it inside the packer, unlike what has already been mentioned, they are mostly used for lower completions which allows that by means of a fairly long rubber with lengths between 4-20 $\mathrm{ft}$ approximately, they adhere to the walls of the open hole and the seal can be generated. In addition to the above, this type of packer has also been used in special cases in upper completion, since, they present smaller OD to normal completion packers and can be installed in wells with casing restriction.

Swellable seating: This type of packer does not have slips and its seating process acts by placing the elastomer of the rubber in contact with the well fluid achieving its

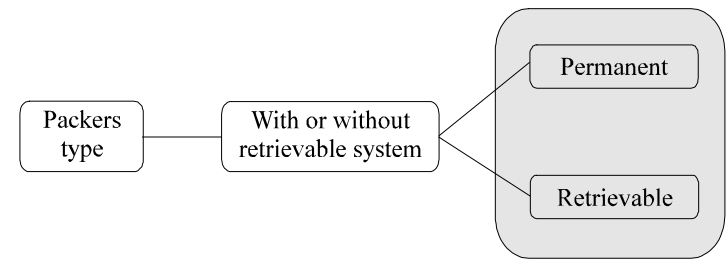

Fig. 6:With or without retrievable system categories

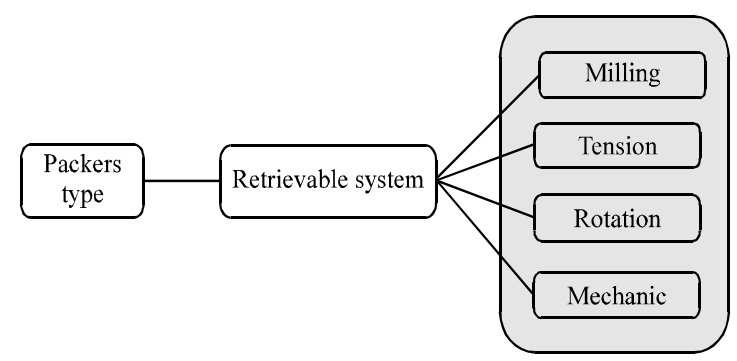

Fig. 7: System retrievable categories

swelling. There are classified as swellable in water or oil based fluids. In addition as inflatable seating packers, they are used for lower completions which allows that by means of a fairly long rubber with lengths between 4-20 ft approximately, they adhere to the walls of the open hole and can generate the seal.

Inflatable and swellable seating systems are more related to lower completion and hydraulics, hydrostatic and mechanical systems are more related to upper completion packers, the latter significantly influence the completion design to communicate the fluids from bottom to surface where they impact on the initial condition at the time of seating the packers and these on the final conditions of service for the completion stress analysis technique (Fig. 6). This category is commonly used by research or companies which is divided into permanent and retrievable.

Permanent packer: These packers do not have a retrievable system and would remain permanently in the well, they can be subdivided into no-integral packer (seal bore) for upper completion which can be recovered by milling the packer and the Inflatable or swellable packer, used for lower completions that due to their characteristic in this type of completion would be permanently in the well.

Retrievable packer: These packers have a retrievable system and are generally all the packers mentioned the integral and the non-integral (Seal bore) retrievable (Fig. 7). This category subdivides by retrieve systems of completion packers which are detailed in Fig. 7 . 
Milling retrieve: This system was already mentioned in the previous category which allows recovering permanent non-integral packers (seal bore) by milling the upper slips and recovering the rest of the packer avoiding leaving fish in the well.

Tension retrieve: This retrievable system works pick up the string generating enough tension to break the release pins present in the packer. This system is characteristic for integral hydraulic and hydrostatic packers.

Rotation retrieve: This retrievable system works by turning the string enough to move a system type J or L, this system is relatively new and was created in order to create a retrievable system that would not be affected by the tubing stress as if it is, tension retrieve system. This system is applied only to the integral packers of hydraulic seating with the purpose of having greater resistance in strings of selective injection where the cooling of the string affects in a critical way the stress. In addition to the above, it must be borne in mind that this release system is affected by the same as the mechanical system where it

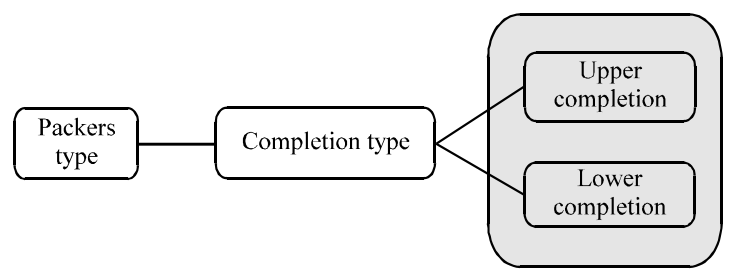

Fig. 8: Type of completion

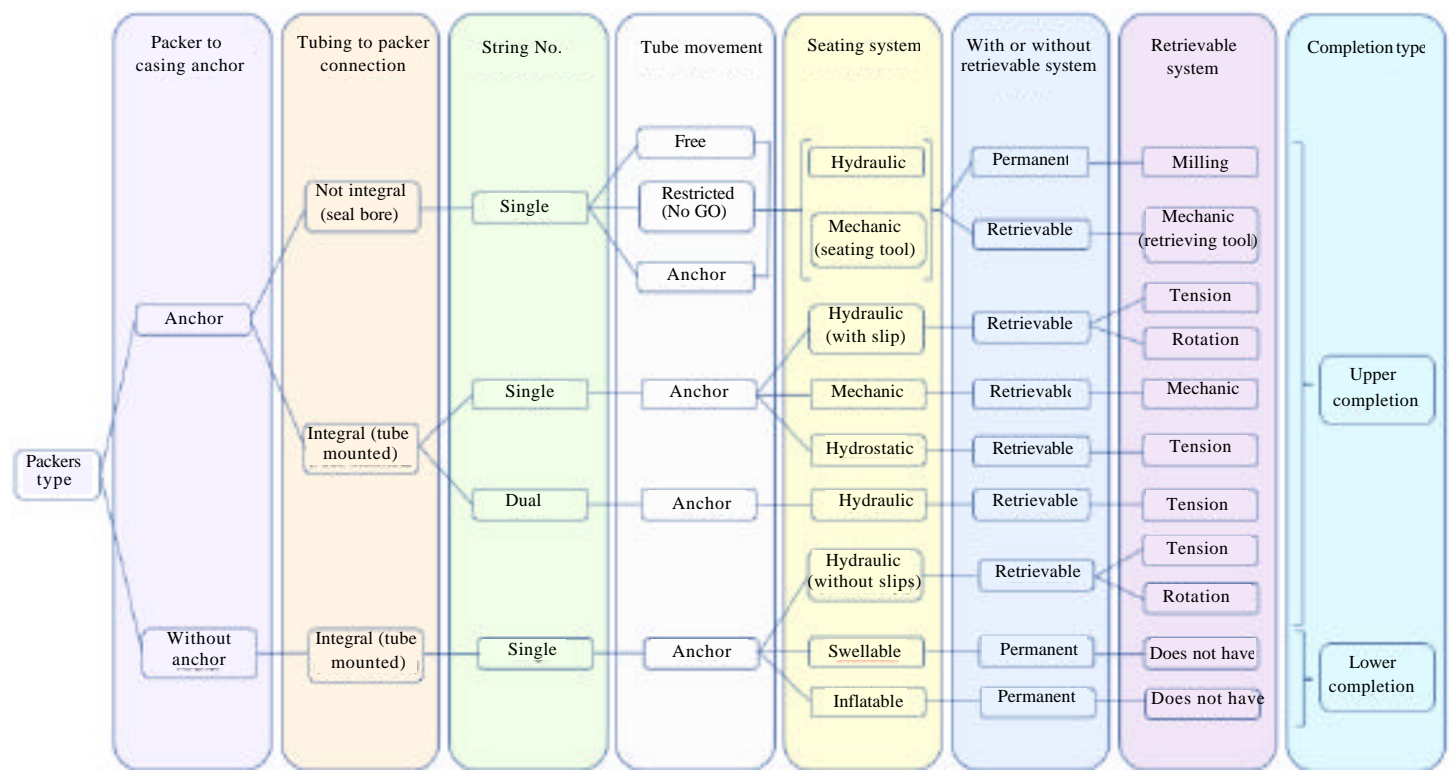

Fig. 9: Relation packer classification cannot be installed in deviated wells or high DLS because the torque required for the release does not reach the depth of packer and cannot be released.

Mechanical retrieve: This mechanical retrievable system uses a combination of actions between tension, compression and rotation in the same way to the seating mechanical system. This system is not usually affected by the tubing stress and also presents restrictions in the case of deviated wells or high DLS.

The retrieve systems are important, not only for the liberation operative processes but also for the completion design, either for the adequate selection of the packer type and in the evaluation of tubing stress analysis where the packers with tension retrieve systems are one of the most affected because limits the maximum tension that will completion support.

The category by type of completion have already been described during this document but there are packers that apply for each of them (Fig. 8 and 9).

Upper completion: The packers that are applied for this type of completion are all the packers classified as anchored in the packer to casing anchor category, this means all those packers that have slips and the packers without anchoring (without slips) are the hydraulic packers called Tandem. In some special occasions, inflatable packers are used in areas of great casings restrictions or collapses where having a lower OD than the anchored packers will reach areas where the others are not able. 
Lower completion: The packers that are applied for this type of completion are few, the conception of selectivity and isolation is related to the upper completion, although, in some occasions it is necessary selectivity in open hole in the reservoir area, for this reason swellable and inflatable packers are used for this category because due to its design of longer elastomers and its greater $O D$ deformation allows adhere to reliable way to the open hole irregular shape generating the appropriate seal.

According to each of the packers classifications and descriptions mentioned above, there is an intrinsic relationship between each of them Fig. 9. In Figure 9, it is provided clearly and concisely how each packer is classified, to what category it remains and how it applies for each type of completion. In addition, it must be taken into account that understanding the classifications of a packer makes easier the selection during tool selection or tubing stress analysis (Fig. 9).

\section{CONCLUSION}

We made a review of the different classifications and different categories that a packer could present including new technologies of packers type, retrievable systems, operational and design applications, since, they are currently used in the industry. In addition, we made a characterization, description and recommendations for each of them, detailing how they impact directly on the completion design, selection and in the tubing stress analysis.

\section{REFERENCES}

Anonymous, 2017a. Completion packer. Schlumberger, Houston, Texas, USA. https://www.slb. com/services/completions/packers.aspx

Anonymous, 2017b. Production packer. Weatherford, Houston, Texas, USA.

Bellarby, J., 2009. Well Completion Design. 1st Edn., Elsevier, Amsterdam, Netherlands, ISBN: 978-0-444-53210-7, Pages: 695.

Calderon, A., 2017. [Analysis of the Impact of Tandem Packages (Without Anchoring) as Intermediate Packings on the Pipeline Efforts in Completion of Selective Strings]. South Colombian University, Neiva, Huila, Colombia, (In Spanish).

Guo, B., X. Liu and X. Tan, 2017. Petroleum Production Engineering. 2nd Edn., Gulf Professional Publishing, Elsevier, Houston, Texas, USA.,

Hughes, B., 2017. Packer System Catalog. Baker Hughes a GE Company, Houston, Texas, USA.,.

Patton, L., 1987. Petroleum Engineering Handbook. Society of Petroleum Engineer, Moscow, Russia,. 